\title{
Decontamination of biocidal loaded wooden artworks by means of laser and plasma processing
}

\author{
Birgit Angelika Schmidt ${ }^{1}$, Simone Pentzien ${ }^{1}$, Andrea Conradi ${ }^{1}$, Jörg Krüger ${ }^{1 \star}$, \\ Constanze Roth ${ }^{2}$, Oliver Beier ${ }^{2}$, Annett Hartmann ${ }^{2}$, Bernd Grünler ${ }^{2}$ \\ 1 Bundesanstalt für Materialforschung und-prüfung (BAM), Unter den Eichen 87, 12205 Berlin, \\ Germany \\ 2 INNOVENT e.V., Prüssingstraße 27 B, 07745 Jena, Germany \\ * Corresponding author: joerg.krueger@bam.de
}

\begin{abstract}
Many wooden artworks are contaminated by DDT (dichlorodiphenyltrichloroethane) as a result of a surface treatment by means of the liquid preservative Hylotox-59 ${ }^{\circ}$. It was used until the end of the 1980s. DDT crystal structures are formed on the wood surfaces by the "blooming" of chlorine compounds. In addition to an aesthetic disturbance, it is assumed that DDT represents a health risk. Even decades after applying, the toxins in the wood preservatives are still detectable because they are of low volatility in many wood samples. Contaminated waste wood with natural biocide ageing, gilded and wood carved elements of an old picture frame and wooden samples with paint layers were provided by the Schlossmuseum Sondershausen. Non-contact procedures using laser and plasma appear reasonable to remove the DDT crystals. During the experiments, health and safety issues for the operator have to be taken into account.

The removal of DDT was evaluated employing femtosecond and nanosecond laser radiation and cold atmospheric plasma techniques with different working gases (air, nitrogen, and argon). Before laser application, a chlorine measurement representing the DDT density on the wooden surface is done by X-ray fluorescence (XRF) analysis as reference. After laser processing, the XRF analysis is used again at the same surface position to determine the depletion rate. Additionally, a documentation and characterization of the sample surface is performed before and after laser and plasma treatment using optical microscopy (OM). For plasma processing with various systems a chlorine measurement is done by gas chromatographic-mass spectrometry (GCMS) analysis.
\end{abstract}

Keywords: decontamination, DDT, wooden artworks, femtosecond laser, nanosecond laser, cold atmospheric pressure plasma

\section{Introduction}

The main focus of this paper is the so-called Golden Carriage from the Schlossmuseum Sondershausen (see Fig. 1). It belongs to the collection of the Thuringian Foundation of
Palaces and Gardens. The Golden Carriage is a princely state coach of the Grand Carrosse type developed in France since the second half of the $17^{\text {th }}$ century. The type of the vehicle, its design and partly also its equipment indicate that this coach was built around 1710 in Paris [1]. 


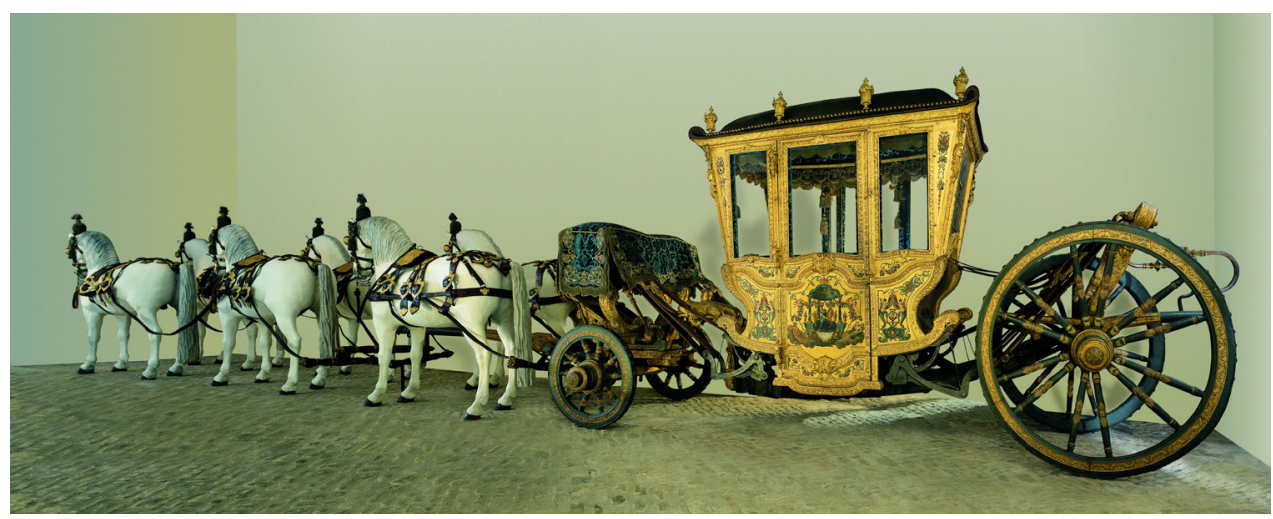

Fig. 1. The Golden Carriage. Copyright: Schlossmuseum Sondershausen. Photograph by U. Kneise.

Based on records [2], the use of Hyloto $x-59^{\odot}$, a DDT and lindane containing preparation against vermins, was firstly documented on construction parts of the Golden Carriage in 1969. Hylotox-59 ${ }^{\odot}$ as a liquid wood preservative was extensively used until the end of the 1980s in the former GDR. At that time, it was a very common wood preservative. It contains 3.5\% DDT and $0.5 \%$ lindane in a solvent mixture.

Studies have shown that the amount of biocide-contaminated objects in German cultural institutions like museums is very high, especially in the textile and natural historical fields [3].

From today's point of view, biocidal substances and agents represent a high risk with respect to a health hazard and environmental impact as well as potential object damage [4]. Therefore, it is of great importance to protect employees of collections and visitors of exhibitions in developing methods for reducing or even removing the toxic components from the contaminated materials.

In addition to dry processes for removing the crystalline efflorescence on surfaces, today a variety of wash procedures is used, among which the vacuum washing method is the most famous one. Furthermore, decontamination is performed by means of supercritical carbon dioxide and also allows a deep cleaning. Especially for profiled or carved surfaces and objects of art that cannot be exposed to moisture, the non-contact laser technology is a suitable alternative [5].

DDT crystal structures are formed on surfaces by the "blooming" of chlorine compounds as can be seen on the magnification of a surface of a wooden sample in Fig. 2. The aim of the studies presented here is to remove those DDT crystal structures from the surface. The removal of DDT was evaluated by employing femtosecond and nanosecond laser radiation and cold atmospheric plasma techniques as an alternative

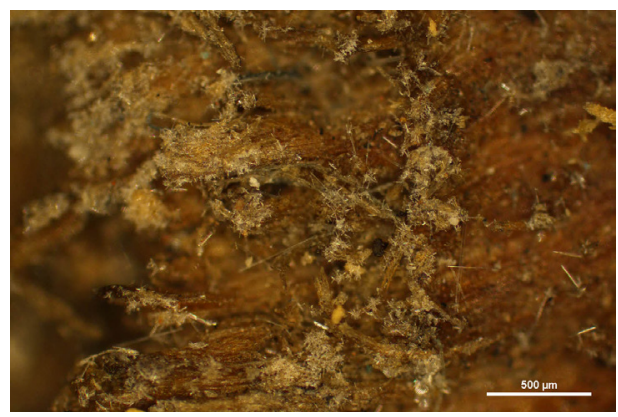

Fig. 2. Optical micrograph of DDT crystal structures ("blooming") on a contaminated wooden sample; scale bar represents $500 \mu \mathrm{m}$ 
or in addition to mechanical or chemical cleaning methods.

Experiments were performed on test samples as well as on original construction elements of the Golden Carriage. The results should give a guideline whether these methods can successfully be performed on these artworks.

\section{Materials and methods}

\subsection{Description of samples}

The Schlossmuseum Sondershausen provided three different types of samples. Contaminated wood samples with natural biocide ageing namely two strips which served as the backing protection of an easel painting (Fig. 3) and an original construction component of the Golden Carriage (Fig. 4) were investigated. In addition to crystalline DDT efflorescence, they also showed a light soiling, which proved to be an advantage for the use of lasers.

Furthermore, three gilded and stucco carved decorative elements of an old picture
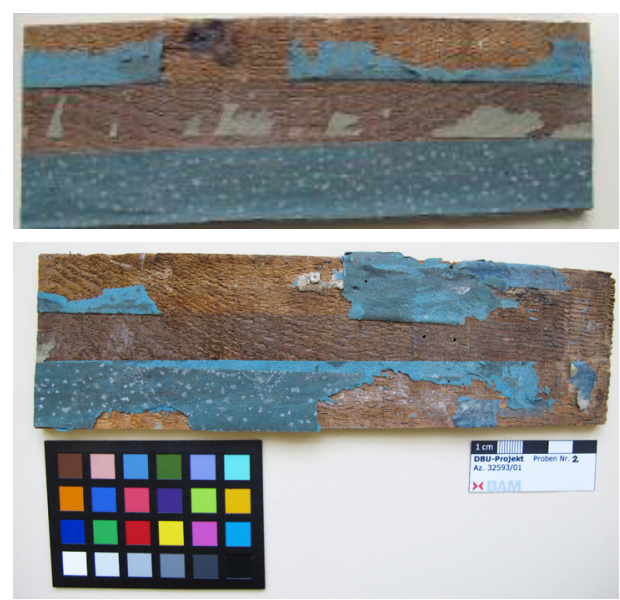

Fig. 3. Contaminated wood from the backing of an easel painting.

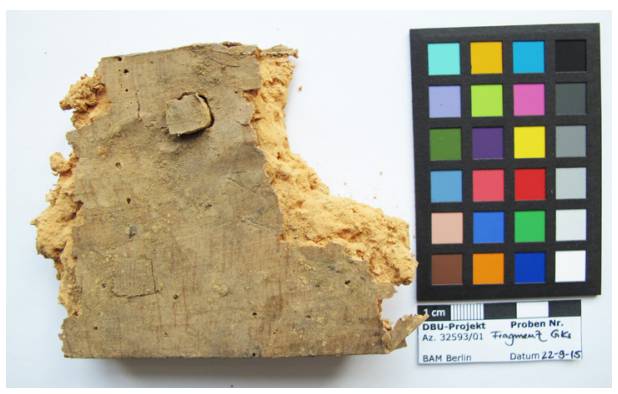

Fig. 4. Contaminated wood from the Golden Carriage.

frame (Fig. 5) as well as two wooden samples with different paint layers (Fig. 6) were tested.

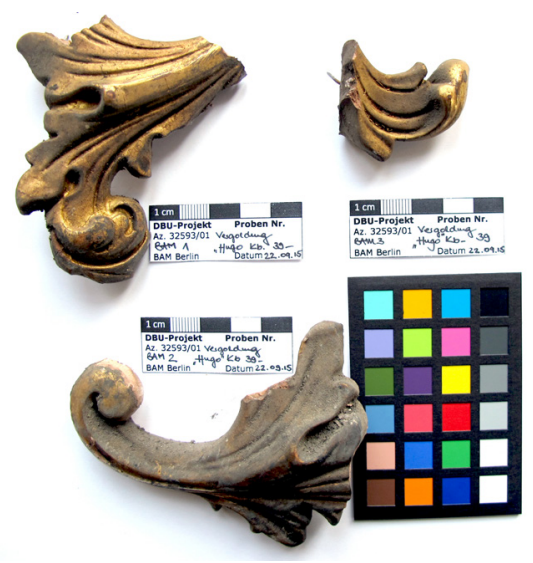

Fig. 5. Gilded, stucco carved objects.

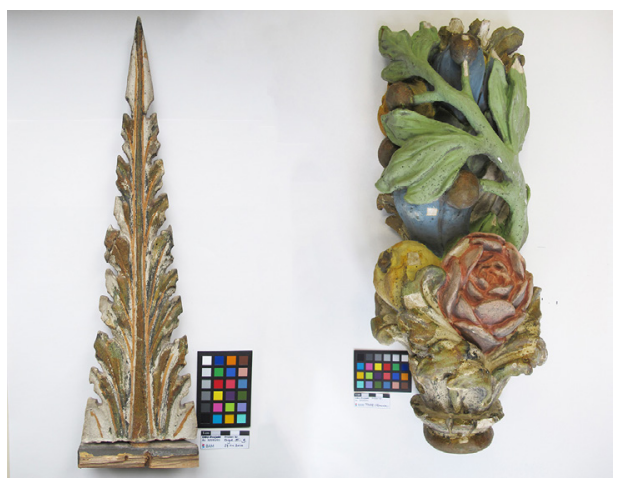

Fig. 6. Wood with paint layers. 


\subsection{Experimental methods}

In the following, details of the contactless laser and plasma treatment are described. Before and after laser application, a chlorine measurement is done by $\mathrm{X}$-ray fluorescence (XRF) analysis at exactly the same surface position. Chlorine depletion rates can be calculated using these data. Additionally, a documentation and characterization of the sample surface is done before and after laser and plasma treatment using optical microscopy.

\section{Energy dispersive $X$-ray fluorescence}

The X-ray fluorescence analysis is a non-destructive spectroscopic method, which is used for the qualitative and quantitative determination of the elemental composition of sample material. The surface of the object is thereby irradiated with X-rays. Element-specific secondary X-rays are emitted. Here, the X-ray spectra were recorded by means of a Fischer Scope XDAL XRF (Helmut Fischer GmbH + Co KG, Sindelfingen, Germany) equipped with a tungsten anode and operated at $10 \mathrm{keV}$ with a nickel filter. The X-ray spot diameter amounted to 0.7 $\mathrm{mm}$ and the data acquisition time was 60 seconds.

\section{GC MS measurements}

GC MS (gas chromatograph/mass spectrometer) is a combined analyzing system. The gas chromatograph serves to separate the substance mixture to be examined and the mass spectrometer for the identification and, if appropriate, also the quantification of the individual components. At INNOVENT the DDT content of samples was measured by using Headspace GC MS. The samples were heated in headspace vials and the evaporated phase was analyzed.

\section{Ultra short pulsed laser system}

The Ti:sapphire laser system (Compact Pro, Femtolasers) provides 30-fs laser pulses at $800 \mathrm{~nm}$ wavelength and a repetition rate of $1000 \mathrm{~Hz}$. Laser pulse energies of up to $1 \mathrm{~mJ}$ can be generated. The laser pulse energies were measured by means of a pyroelectric detector (Coherent). The laser pulses were focused by a spherical dielectric mirror of $500 \mathrm{~mm}$ focal length. A laser beam radius $\left(1 / e^{2}\right)$ of about $40 \mu \mathrm{m}$ was set on the sample surface. In contrast to the short pulse laser system, the object was moved relative to the laser beam employing linear $\mathrm{x}-\mathrm{y}-\mathrm{z}$ translation stages. Laser-treated areas of up to $5 \mathrm{~mm} \times 8$ $\mathrm{mm}$ were reached. The number of pulses per spot $\left(\mathrm{N}_{\mathrm{eff}}\right)$ was changed between 5 and 10 .

\section{Short pulsed laser system}

The BAM prototype laser cleaning workstation was described in detail by Kautek and Pentzien [6]. Some important parameters should be given here. The samples were exposed to a pulsed Q-switched Nd:YAG-laser (DINY $p Q$, IB Laser) generating 7-ns laser pulses at $532 \mathrm{~nm}$ wavelength and 10-ns laser pulses at $1064 \mathrm{~nm}$ wavelength at a pulse repetition frequency of $500 \mathrm{~Hz}$. Pulse energies were measured using an energy meter (Nova, Ophir). The spatial beam profile was Gaussian. Beam radii $\left(1 / e^{2}\right)$ of about $140 \mu \mathrm{m}(532$ $\mathrm{nm}$ wavelength) and $141 \mu \mathrm{m}(1064 \mathrm{~nm})$ on the sample surface were achieved. The laser beam was scanned over the samples reaching a field size of $2 \mathrm{~mm} \times 2 \mathrm{~mm}$. The maximum laser fluence in the focal spot $\left(\mathrm{F}_{0}\right)$ was varied by more than one order of magnitude for both wavelengths. The number of pulses per spot $\left(\mathrm{N}_{\mathrm{eff}}\right)$ was changed between 1 and 100 . The laser cleaning system is computer controlled and equipped with an exhaust system to remove ablation products. The cleaning action can be monitored on a computer 
screen. The laser-processing compartment fulfils Laser Class I conditions.

\section{Atmospheric Pressure Plasma}

In general, plasma is referred to as the fourth aggregate state besides solid, liquid and gaseous. Plasma is an ionized gas containing charged particles, such as ions and electrons. However, uncharged and partially charged components are also being included. One can differentiate for the different plasma types for example between low pressure and atmospheric pressure plasma as well as cold plasmas or discharges in thermal equilibrium. In the project INNOVENT decides to work with cold atmospheric pressure plasma jets, because it is a very variable, mobile and cost efficient technology.

The temperature of cold atmospheric pressure plasma is between 30 to $600^{\circ} \mathrm{C}$. The plasma intensity can be adjusted across the entire spectrum and investigations of plasmas itself were already made in restoration projects [7]. INNOVENT compared two different sources namely the TIGRES Plasma MEF (Tigres GmbH, Marschacht, Germany) (see Fig. 7) and kINPen 09 (neoplas tools $\mathrm{GmbH}$, Greifswald, Germany). This source is very easy to handle, has a gentle performance and is already in use for dermatological treatments [8], while the TIGRES source offers more variations in parameters due to its technical design. Here, results obtained utilizing TIGRES plasma MEF are presented.

The parameters gas type, number of treatments (run) and the distance between the treatment lines (pattern distance) were varied. The process gases during the experiments for the TIGRES plasma MEF were nitrogen, air or a nitrogen-hydrogen-mixture ( $5 \%$ hydrogen). Other parameters were kept constant, the velocity of the substrate relatively to the stationary plasma jet was set to $50 \mathrm{~mm} / \mathrm{s}$, the plasma-substrate distance was $10 \mathrm{~mm}$ and the electrical power $300 \mathrm{~W}$. An evaluation of the chlorine residues was performed with headspace GCMS for DDT peak areas.
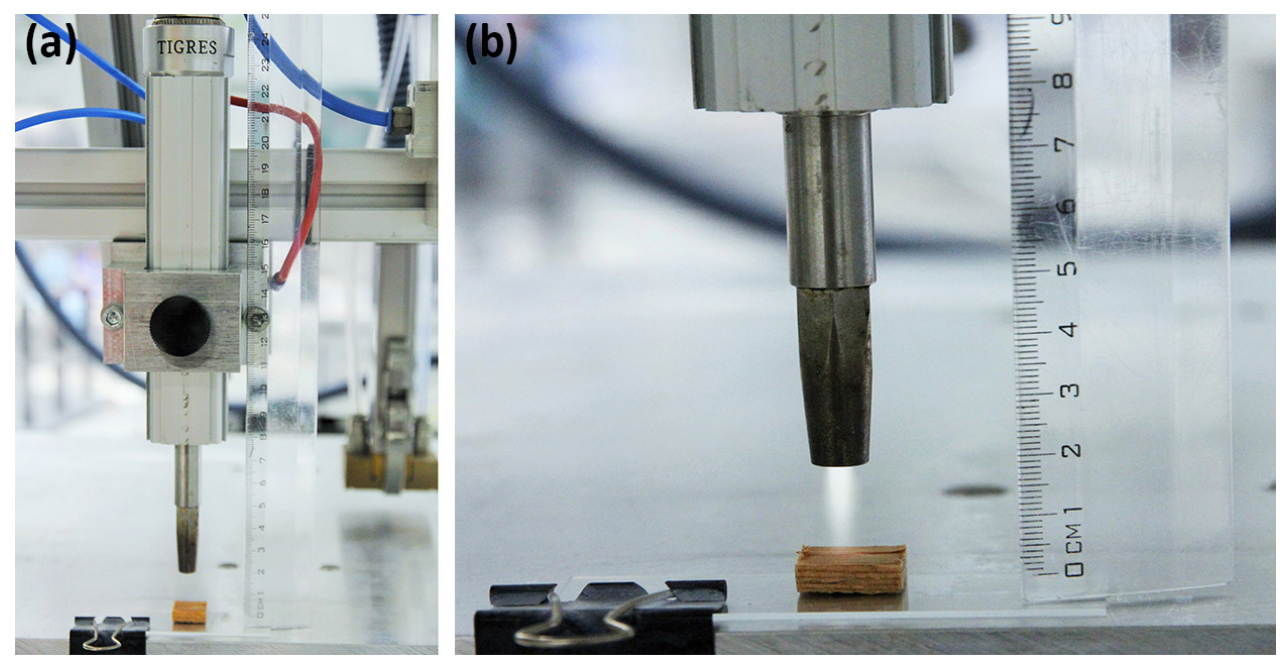

Fig. 7. Total view of TIGRES plasma MEF (a). Visualization of the discharge using air as process gas (b). Photographer: INNOVENT e.V. 


\section{Results}

Before cleaning experiments were performed, the laser damage thresholds of the sample materials had to be identified. They depend on pulse duration, wavelength and number of pulses per spot. Based on previous cleaning investigations for the restoration of a medieval wooden panel chamber, laser fluences should be limited to $<1.5 \mathrm{~J} / \mathrm{cm}^{2}$ for the use of $1064 \mathrm{~nm}$ laser radiation (and $6 \mathrm{~ns}$ pulse duration) to avoid microscopic wood damage [9]. The use of energy densities $>100$ $\mathrm{J} / \mathrm{cm}^{2}$ leads to significant ablation of beech model material [10]. Therefore, the task is the laser action caused a reduction of the chlorine concentration on the surface as can be seen by a comparison of the chlorine concentration values between Fig. $8 \mathrm{~b}$ and Fig. $8 \mathrm{a}$ within the white frame.

\subsection{Ultra short pulsed laser treatment on contaminated wood}

Test series on contaminated wooden surfaces using ultra short laser pulses led to a chlorine depletion rate of about $75 \%$ at a laser fluence of $\mathrm{F}_{0}=0.13 \mathrm{~J} / \mathrm{cm}^{2}$ and an effective number of pulses per spot of $\mathrm{N}_{\mathrm{eff}}=10$. Figure 9 depicts the relative change of the chlorine content
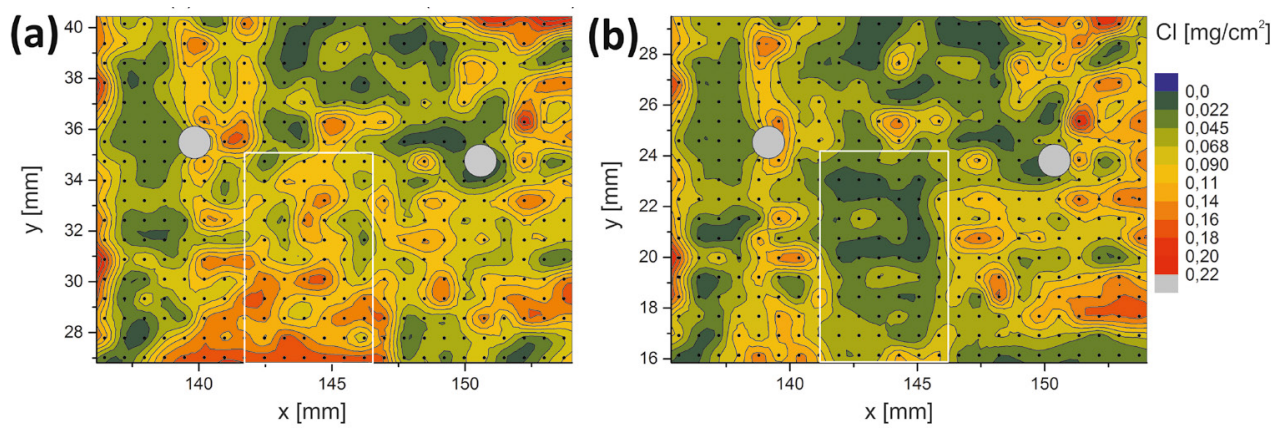

Fig. 8. Chlorine distribution of a selected area on a wood sample before (a) and after (b) laser treatment ( $30 \mathrm{fs}$, $800 \mathrm{~nm}, \mathrm{~F}_{0}=0.13 \mathrm{~J} / \mathrm{cm}^{2}, \mathrm{~N}_{\text {eff }}=10$ ).

to find a laser working range, that means energy density $\left(\mathrm{F}_{0}\right)$ and effective number of pulses per spot $\left(\mathrm{N}_{\mathrm{eff}}\right)$, ideally to be above the cleaning threshold and below the damage threshold of the sample material. As mentioned above, XRF analysis was performed for the determination of the chlorine content before (Fig. 8a) and after laser treatment (Fig. 8b).

Figure 8 shows a comparison of the absolute chlorine concentration of a predefined surface area before and after laser treatment. The white frame marks the area where laser treatment was performed. It is obvious that

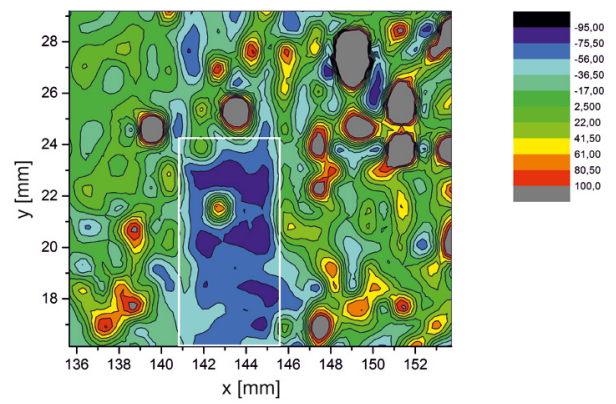

Fig. 9. Relative chlorine distribution plot of a wood sample. The values were obtained by a pointwise calculation according to (XRF signal after laser XRF signal before laser) / (XRF signal before laser) $\times 100 \%$. 
expressed as a percentage. In the violet range indicating the above mentioned depletion rate, the laser treatment was done.

Figure 10 illustrates the original surface contamination on a wood sample (Fig. 10a). Clearly, DDT crystals can be observed on the surface as white efflorescence. Figure $10 \mathrm{~b}$ shows an OM of the sample surface after
The picture in Fig $11 \mathrm{~b}$ depicts the cleaning result in the red frame, while Fig. 11a shows the surface before.

Compared with the ultrashort pulse laser at $800 \mathrm{~nm}$, a slightly lower chlorine depletion rate can be observed with the short pulse laser system. Moreover, based on the micrographs (see Figs. 10 and 11), it can be seen
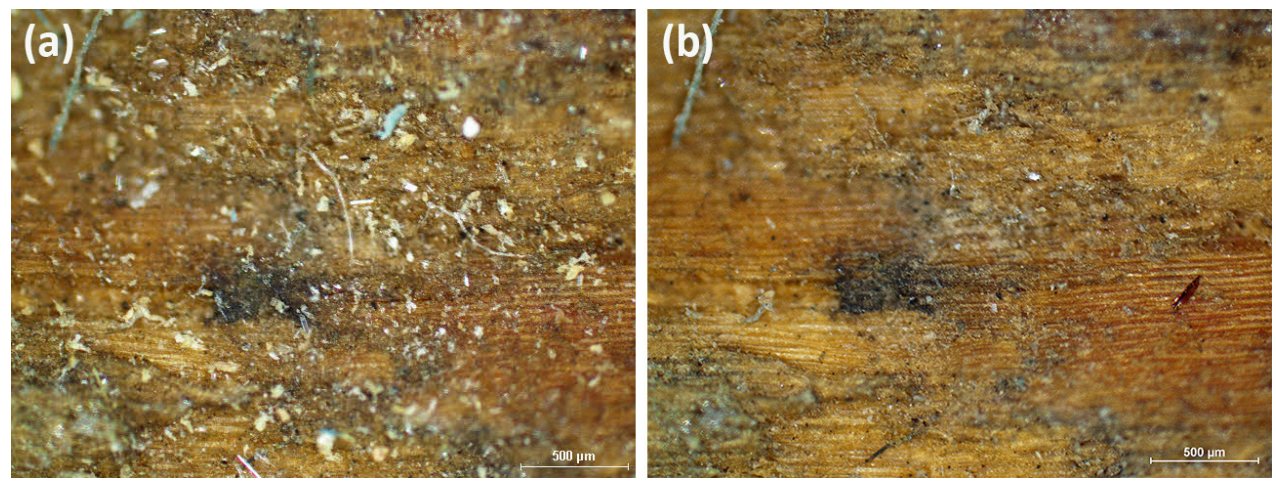

Fig. 10. Optical micrographs of a wooden sample before (a) and after (b) laser irradiation ( $30 \mathrm{fs}, 800 \mathrm{~nm}$ ); scale bars represent $500 \mu \mathrm{m}$.

femtosecond laser treatment of the whole area. The successful cleaning of the surface is demonstrated. Almost no DDT crystals remain on the surface.

\subsection{Short pulsed laser treatment on contaminated wood}

With the short pulsed laser system, it was possible to achieve chlorine depletion rates in the range of $55-70 \%$ employing laser energy densities from $0.4-0.8 \mathrm{~J} / \mathrm{cm}^{2}$ and pulse numbers per spot of 5 and 10. These parameters are above the cleaning threshold and below the damage threshold of the tested material. In addition to the XRF-analysis, OM micrographs of the original surface were created and were compared with micrographs after laser action. that in the femtosecond case a better removal of DDT crystals was achieved compared to the nanosecond laser use.

\subsection{Short pulsed laser treatment on gilded objects}

Several experiments on gilded wooden samples were carried out but even good cleaning results achieved no chlorine reduction due to the fact that there is only a small amount of chlorine on the sample. Therefore, only a removal of dust is needed in this special case. XRF measurements confirmed the low amount of chlorine, too. A uniform cleaning result was obtained on the sample surface with an intact gold layer using laser pulses with $\mathrm{F}_{0}=0.2 \mathrm{~J} / \mathrm{cm}^{2}$ and $\mathrm{N}_{\text {eff }}=5$ (Fig. 12a). If the laser energy density is increased by 


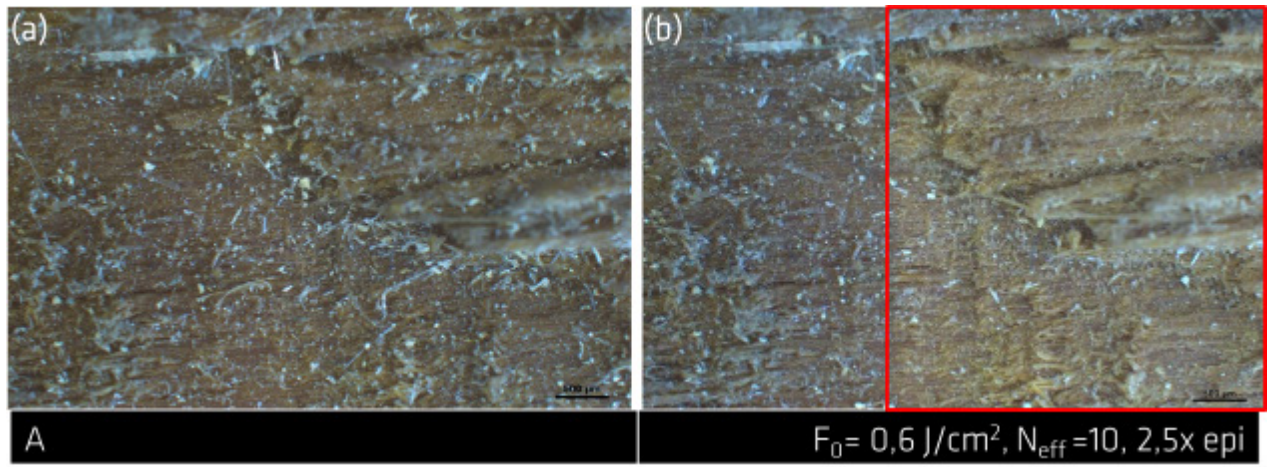

Fig. 11. Optical micrographs of a wooden sample before (a) and after (b) laser irradiation (10 ns, $1064 \mathrm{~nm})$; scale bars represent $500 \mu \mathrm{m}$.

a factor of two only for the same number of pulses per spot, the sensitive gold layer is damaged (Fig. 12b). be determined microscopically due its low layer thickness. The second layer from 1886 is designed as a wood imitation on

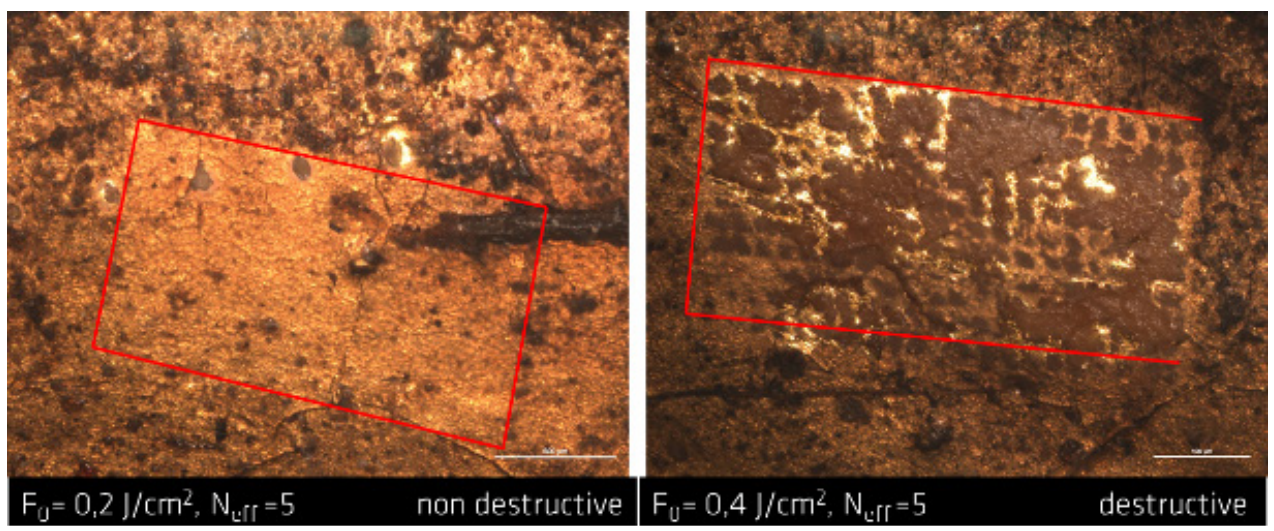

Fig. 12. Optical micrographs of a golden sample after a non destructive cleaning experiment (a) and after a destructive cleaning experiment (b) with laser pulses at a pulse length of $10 \mathrm{~ns}$ at 1064 wavelength; scale bars represent $500 \mu \mathrm{m}$.

\subsection{Short pulsed laser treatment on wood with paint layers}

Investigations were done on wood craft samples with paint layers from the baroque era. The first layer, performed in 1703 , is made of pure white on a chalk ground (probably a polished white layer) and also contains chalk and blanc fixe. It can only an ocher, oil-based primer. The nowadays still visible third layer was performed in 1934 and consists of different oil colours on a yellowish-white, oil-based primer. An OM micrograph (Fig. 13) clearly identifies DDT crystals, therefore cleaning attempts were made. For all different colour regions (brown, white, gold, green, and black), the damage thresholds of the paint layers were 


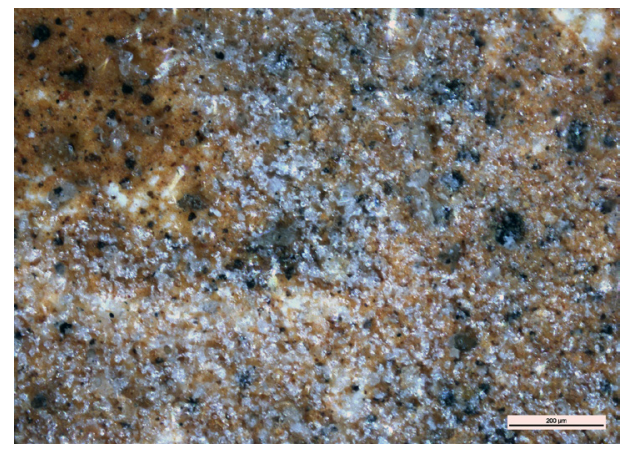

Fig. 13. Optical micrograph of DDT crystal structures ("blooming") on a contaminated wooden sample with paint layers; scale bar represents $200 \mu \mathrm{m}$.

determined. In many cases, these damage thresholds are comparable or even lower than the cleaning threshold to remove DDT of about $0.3 \mathrm{~J} / \mathrm{cm}^{2}$. As a conclusion and with the exception of only two coloured areas (brown and white), it was not possible to remove the DDT crystals without causing damage to the paint layers beneath.

\subsection{Atmospheric pressure plasma on contaminated wood}

In the first series of tests, appropriate parameters for cleaning of wood surfaces were investigated.

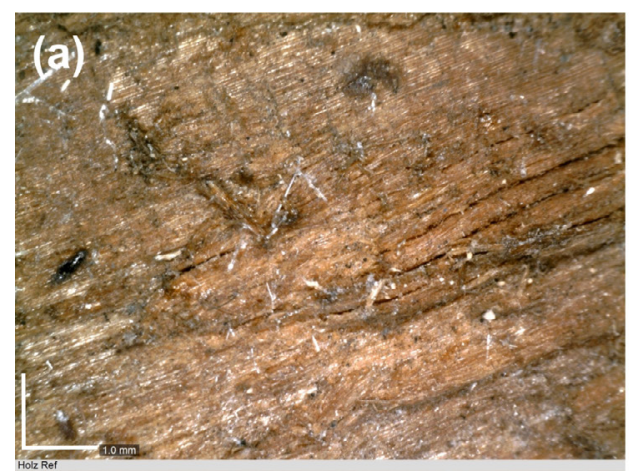

The prerequisites were minimal loading of the surface by the plasma treatment and a significant (damage-free) cleaning effect. Figure 14b shows the plasma cleaning result of a wooden sample from the Schlossmuseum Sondershausen by optical microscopy. Here, nitrogen was used as a process gas with only one plasma treatment run on the surface.

As can be seen after the plasma treatment, a strong decrease of visible DDT crystallites (the white needles in Fig. 14a) at the wooden surface is obtained (Fig. 14b). But it has to be mentioned that for these samples no reproducible depletion quantities could be determined since the original chlorine loading by the wood preservative was not documented or directly known. GC MS measurements revealed here from sample to sample significant differences in DDT concentrations allowing no clear statements for the different treatment conditions. Therefore, new samples were prepared from beech veneers, which had a defined chlorine loading (DDT). INNOVENT has chosen beech veneer, because the Golden Carriage is mainly made of beech. With these samples the plasma treatments were carried out first and the GC MS measurements followed. The results for different types of process gases

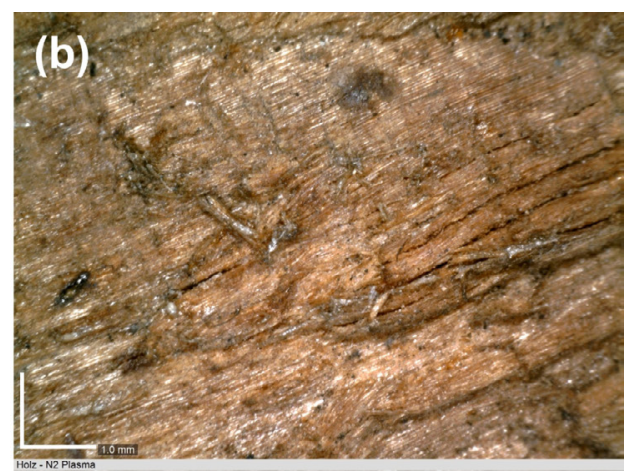

Fig. 14. OM of contaminated wood before (a) and after (b) plasma treatment with nitrogen as process gas; scale bars represent $1 \mathrm{~mm}$. 
(air, nitrogen, nitrogen/hydrogen mixture), a pattern distance of $1 \mathrm{~mm}$ or $3 \mathrm{~mm}$ and the number of treatment runs are shown in Table 1. For each parameter six samples were plasma treated and measured by GC MS. The depletion rate was compared to untreated reference samples measured on the same day to minimize environmental effects.

By varying the type of gas, the distance between the treatment lines (pattern distance) und number of treatments (run) different results could be achieved. At first, all gases show a chlorine (DDT) depletion. For air, the standard deviation was the highest for the same amount of treated samples. Here it could be observed that besides samples with high depletion rates with more than $50 \%$ also low rates of max. $20-30 \%$ occur. In contrast, for nitrogen the standard deviation is lower under the same conditions and trend to decrease with higher numbers of plasma treatments (increase of interaction times - higher energy input). Best depletion results were achieved for nitrogen with a 1 $\mathrm{mm}$ pattern distance and ten treatment runs.
With these parameters a depletion of DDT total volume between $60-70 \%$ is possible and at the same time comparable cleaning results from sample to sample are obvious. First experiments with the nitrogen-hydrogen gas mix show that there is already a similar effect to that of nitrogen in three runs, which will be further investigated.

\section{Conclusions}

The removal of unwanted DDT crystals from wooden artworks as a result of a biocidal treatment in the 1980s with advanced non-contact laser and plasma techniques was performed. Short and ultrashort pulsed lasers and cold atmospheric plasma were used. On wooden samples, a depletion of the chlorine concentration of $55-70 \%$ and $75 \%$ was achieved for 1064-nm nanosecond pulses and $800-\mathrm{nm}$ femtosecond laser pulses, respectively. For the application of 30-fs laser pulses, no crystalline DDT residues remain on the sample surfaces. Using the TIGRES

Table 1. Evaluation results of headspace GC MS peak areas for DDT for different plasma treatment parameters

\begin{tabular}{lcccc}
\hline $\begin{array}{l}\text { Type } \\
\text { of Gas }\end{array}$ & $\begin{array}{c}\text { Pattern } \\
\text { distance }\end{array}$ & Run & $\begin{array}{c}\text { Mean value decontamination } \\
\text { rate / total volume DDT }\end{array}$ & $\begin{array}{c}\text { Standard variation of decontam- } \\
\text { ination rate / total volume DDT }\end{array}$ \\
\hline $\mathrm{N}_{2}$ & 3 & 3 & $50 \%$ & $14 \%$ \\
\hline $\mathrm{N}_{2}$ & 3 & 5 & $35 \%$ & $14 \%$ \\
\hline $\mathrm{N}_{2}$ & 3 & 7 & $37 \%$ & $10 \%$ \\
\hline $\mathrm{N}_{2}$ & 3 & 10 & $65 \%$ & $8 \%$ \\
\hline $\mathrm{N}_{2}$ & 1 & 5 & $60 \%$ & $6 \%$ \\
\hline $\mathrm{N}_{2}$ & 1 & 7 & $65 \%$ & $8 \%$ \\
\hline $\mathrm{N}_{2}$ & 1 & 10 & $70 \%$ & $9 \%$ \\
\hline $\mathrm{N}_{2} \mathrm{H}_{2}$ & 3 & 1 & $29 \%$ & $10 \%$ \\
\hline $\mathrm{N}_{2} \mathrm{H}_{2}$ & 3 & 2 & $52 \%$ & $6 \%$ \\
\hline $\mathrm{N}_{2} \mathrm{H}_{2}$ & 3 & 3 & $51 \%$ & $10 \%$ \\
\hline Air & 3 & 3 & $52 \%$ & $21 \%$ \\
\hline Air & 1 & 3 & $56 \%$ & $14 \%$ \\
\hline Air & 1 & 5 & $51 \%$ & $18 \%$ \\
\hline Air & 1 & 7 & $47 \%$ & \\
\hline
\end{tabular}


plasma MEF with nitrogen as working gas depletion rates of $60-70 \%$ could be achieved with a relatively high number of treatment runs. Initial experiments with nitrogen-hydrogen gas mix show that similar effects can be achieved after three runs.

Gilded wooden objects with high soiling but low DDT contamination can be cleaned successfully with nanosecond laser pulses. Based on colour changes, cleaning of only a few selected wooden samples with paint layers is possible.

\section{Acknowledgements}

The authors would like to thank Mario Sahre and Thorid Lange (BAM 6.7) for the XRF measurements and Karolina Barnikol (INNOVENT) for GCMS measurements. Fruitful discussions with Antje Pohl are gratefully acknowledged. This work was financed by the Deutsche Bundesstiftung Umwelt DBU (German Federal Environmental Foundation).

\section{References}

[1] B. Bärnighausen, H. Bärnighausen, Die Goldene Kutsche von Schloß Sondershausen. Amtlicher Führer Special, Deutscher Kunstverlag GmbH München, Berlin 2001,pp. 7.

[2] B. Bärnighausen, H. Bärnighausen, Die Goldene Kutsche von Schloß Sondershausen. Amtlicher Führer Special, Deutscher Kunstverlag GmbH München, Berlin 2001, pp. 37.

[3] H. Tello, B. Paz, „Über den Einsatz von Bioziden in naturkundlichen, botanischen und musealen Sammlungen - Rückblick und Ausblick“, in: P. Zalewski (Ed.), Biozidbelastete Kulturgüter- Grundsätzliche Hinweise und Texte zur Einführung in die Problematik. Bericht über das EU-/ ESF-Projekt „Kleine und Mittlere Unternehmen und Wissenschaft im Dialog. Dekontamination von Kulturgütern“, Frankfurt (Oder), 2014, pp. 107-124.
[4] H. Tello, „Die Problemlage der Kontamination von Kunst- und Kulturgütern hervorgerufen durch den Einsatz von Bioziden im Land Brandenburg", in: P. Zalewski (Ed.), Biozidbelastete KulturgüterGrundsätzliche Hinweise und Texte zur Einführung in die Problematik. Bericht über das EU-/ ESF-Projekt „Kleine und Mittlere Unternehmen und Wissenschaft im Dialog. Dekontamination von Kulturgütern“, Frankfurt (Oder), 2014, pp. 19.

[5] E. Jelen, K. Püschner, "Dekontamination biozidbelasteter Kunst- und Kulturgüter aus Holz", in: $\mathbf{L a}$ seranwendung in Restaurierung und Denkmalpflege. Grundlagen-Chancen-Perspektiven (Proceedings), Osnabrück, Germany, January 30-31, 2009, G. Wiedemann, U. Klotzbach, U. Bauer-Bornemann (Eds.), Fraunhofer IRB Verlag, Stuttgart 2009, pp. 165-170.

[6] W. Kautek, S. Pentzien, "Laser cleaning system for automated paper and parchment cleaning", in: Springer Proceedings in Physics 100 (2005), Proceedings LACONA $V$, Osnabrück, Germany, September 15-18, 2003, K. Dickmann, C. Fotakis, J. F. Asmus (Eds.), pp.403-410,DOI: 10.1007/3-540-27176-7_51.

[7] PANNA - Plasma and Nano for new age soft conservation, closed Project in EU Frame Programme 7 (FP 7), Project ID: 282998, 2011-2014. http://cordis. europa.eu/project/rcn/101319_en.html (accessed: 26.06.2017).

[8] T. von Woedtke, K.-D. Weltmann, „Grundlagen der Plasmamedizin“, Der MKG-Chirurg, Ausgabe 4/2016, https://www.springermedizin.de/grund lagen-der-plasmamedizin/10981948, (accessed: 26.06.2017).

[9] G. Wiedemann, M. Schulz, J. Hauptmann, H.-G. Kuscha, S. Müller, M. Panzner, H. Wust, "Laser cleaning applied in the restoration of a medieval wooden panel chamber at Pirna", Journal of Cultural Heritage 1 (2000), pp. S247-S258, DOI: 10.1016/ S1296-2074(00)00133-3.

[10] M. Panzner, G. Wiedemann, K. Henneberg, R. Fischer, T. Wittke, "Experimental investigation of the laser ablation process on wood surfaces", Applied Surface Science 127-129 (1998), pp. 787-792, DOI: 10.1016/S0169-4332(97)00743-5. 
